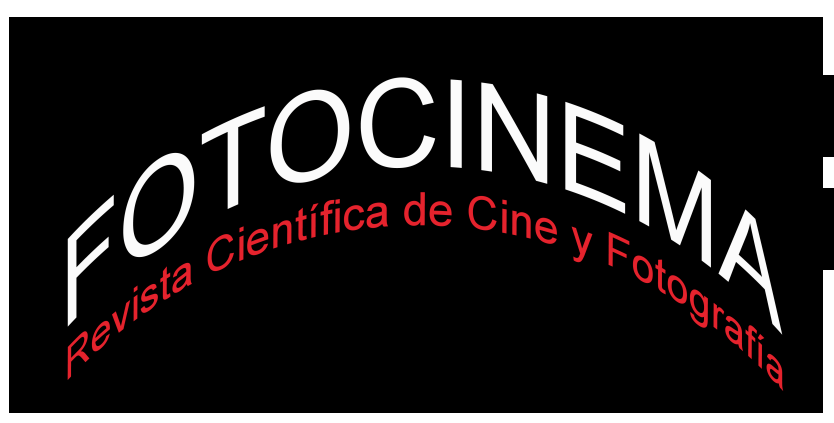

REVISTA CIENTÍFICA DE CINE Y FOTOGRAFÍA

ISSN 2172-0150 No 9 (2014)

Recibido 21-01-2014 / Aceptado 17-03-2014

Preprint 18-07-2014 / Publicado 23-09-2014

\title{
ELIPSE, HISTÓRIA, POLÍTICA, MEMÓRIA. LAS MARIMBAS DEL INFIERNO E O SOM AO REDOR
}

\section{ELLIPSE, HISTORY, POLITICS, MEMORY. LAS MARIMBAS DEL INFIERNO AND O SOM AO REDOR}

\author{
Sebastião Guilherme Albano \\ Universidade Federal do Rio Grande do Norte, Brasil \\ sgac@ufrnet.br
}

\section{Resumo:}

O texto versa acerca da constante da figura da elipse no cinema contemporâneo, especialmente em sua habilidade para incorporar conteúdos associados à manifestação da história, da memória e da política em sentido amplo. Os modos de manifestação desse tropo franqueiam a reflexão a propósito das variantes expressivas e de substância do audiovisual latinoamericano, aqui, com o intuito de análise, reduzido a dois expoentes da nova safra de filmes para cinema, Las marimbas del infierno (Julio Hernández Cordón, 2009) e $O$ som ao redor (Kleber Mendonça Filho, 2012). Quando se fala em elipse se de recordar que se trata de uma figura de sintaxe de supressão ou suspensão, muito vinculada com a reticência (outra figura), o que a leva a indicar sentido ainda quando não apareçam signos ostensivos para sua composição.

\begin{abstract}
:
This text deals about the figure of the ellipse in contemporary cinema, particularly in its ability to incorporate signs of History, memory and politics. Many modes of manifestation of this trope enable a broadly reflection on other variants of the Latin American audiovisual, here, with the aim of analysis, reduced to two exponents of the new wave of motion pictures, Las marimbas del infierno (Julio Hernández Cordón, 2009) and $O$ som ao redor (Kleber Mendonça Filho, 2012). Once we say ellipse, we have to recall its sintatic function of vanishing and suspending, related with the reticences (another figure), which organize some senses despite with no ostensive sign to its compose.
\end{abstract}

Palavras-chave: Elipse; política; memória; história; cinema.

Keywords: Ellipse; Politics; Memory; History; Cinema.

Palabras clave: Elípsis; política; memoria; historia; cine. 


\section{Resumen:}

El estudio reflexiona sobre la constancia de la figura de la elipsis en el cine contemporáneo, en especial en su habilidad de incorporar contenidos asociados a las manifestaciones de la historia, la memoria y de la política en sentido amplio. Los modos de manifestación del tropo posibilitan la reflexión sobre otras variantes expresivas y de substancia en el audiovisual latinoamericano, aqui, con un afa de análisis, reducido a dos ejemplares de la nueva ola de películas para la pantalla grande, Las marimbas del infierno (Julio Hernández Cordón, 2009) y O som ao redor (Kleber Mendonça Filho, 2012). Cuando hablamos de elipsis hay que acotarla a las figuras sintácticas de supresión o de suspensión, muy vinculadas a la reticencia, lo que hace que indique sentido aun cuando no aparezcan los signos ostensivos para la formación del mismo. Por lo tanto, al decir que la elipsis puede desencadenar la emergencia de otras variantes expresivas en las dos películas examinadas nos referimos a que si nada más prepara o indica el sentido, como se tratan de obras tropológicas, otras figuras lo producen en su lugar, tales como la metalepse, la metáfora, la metonimia, la sinécdoque, el oxímoron, etc. Sin embargo, no resaltaremos tal efecto de sustitución, pero sí tratatemos de aludir a las interacciones provocadas por su empleo entre eventos políticos y sociales ya codificados por disciplinas como la historia y por funciones del pensamiento como la memoria, aunque plasmadas en un discurso.

\section{Introdução breve}

O texto que se segue tem dois momentos. O primeiro está dedicado a um feixe de temas que habitam o universo audiovisual contemporâneo, com certa ênfase para as noções destacadas no título, comentadas fora da ordem estabelecida acima a fim de evitar uma hierarquia valorativa. O segundo propõe um comentário analítico dos filmes latino-americanos Las marimbas del infierno (Julio Hernández Cordón, 2009) e $O$ som ao redor (Kléber Mendonça Filho, 2012) à luz dos enunciados pressupostos. Tencionamos alcançar um nível de reflexão argumentativa, descritiva e interpretativa que proponha o tropo da elipse como organizador de boa parte da sintaxe 
figurativa que mobiliza os sentidos sociais dos filmes. A elipse se apresenta assim como locus em que os embates materiais e simbólicos da contemporaneidade alcançam um desempenho inteligível. Tome-se a elipse como aquela figura retórica sintática de supressão, isto é, que escamoteia ou simplesmente prescinde de informação temporal ou espacial (narrativa ou descritiva) que se considera determinante para o sentido de partes do texto ou de seu todo, isto é, que o encerra sem o recurso da explicitação.

Em face de considerarmos uma tradição narrativa latino-americana a remissão a tópicos chave das ciências sociais em textos literários e fílmicos, em seus registros de prosa e longa-metragem de ficção, tratamos de sublinhar o modo em que a elipse mobiliza ora a história ora a memória para rearticular experiências relativas aos eventos permeados pela inépcia das instituições modernas, a violência organizada endêmica e o patriarcalismo. Reitera-se que se considera a elipse aqui como uma figura retórica de sintaxe que propicia a supressão ou a suspensão dos significados e dos sentidos dos filmes. Pontualmente, o que vamos dizer acerca dos filmes é que a elipse permite articular a diegese com o mundo da vida ou ao menos com a interpretação das ciências humanas e sociais, como a História, ou condiciona ainda que figuradamente o mundo projetado pelo filme com o mundo da vida, com efeito uma distinção meramente instrumental aqui.

\section{Marco teórico e metodologia}

Em fins do século XVIII a crise do antigo regime e a onda de revoluções (burguesas ou anti-coloniais) na América e na Europa propiciaram a escalada de proposições concernentes ao campo epistemológico da história. Constituindo-se como disciplina, suscitou a fixação de uma constelação semântica relativa à busca pelo passado social dos estados-nação jovens, portanto, em quase todos os estados nacionais (europeus e americanos). Suas energias extremas geraram o hoje alquebrado nacionalismo, naquele então a chave para a renovação do formato de sociedade e suas interpretações. Folga dizer que não falamos do sentimento nacionalista que mesmo antes de ser nomeado como tal se sabe que determinados grupos desenvolvem, mas do 
nacionalismo com raiz cívica, localizado e oficial, precursor de sociabilidades e afetividades que desenharam um certo perfil e cunharam uma face inteligível à vida humana em sociedade. Um formidável motor institucional, não por acaso denominado Leviatã, alavancou o que se publicita como o imaginário moderno ocidental, cujo feitio mais retrógrado permaneceu vigente e hegemônico até pouco tempo e com resíduos ainda visíveis em microrrelatos ajustados a narrativas maiores. Afinal, a história das formações políticas depende de uma história das formações éticas. No pensamento de Hegel, por exemplo, era na História que o Logos (a Razão, a Verdade) se materializava.

No mesmo diapasão, como para afirmar a consonância semântica de um projeto, tempos depois a filologia e a antropologia ascenderiam como canais cognitivos privilegiados das sociedades europeias e europeizadas. Isso posto, reduzindo o alcance temporal do comentário, pode ser que já inspiradas pelas potencialidades da internet, uma parte das discursividades contemporâneas vive um processo cambiante de produção de sentido e geração de imagens (imaginação figurada, não necessariamente figurativa), menos caudatária da representação e das fontes literárias tradicionais, sejam romances, sejam ensaios, artigos, tratados, textos com intenção epistêmica e sobretudo menos apegadas ao nacionalismo tradicional ou mesmo a uma crítica, em clave ensaística, às instituições. Para o cinema, essas fontes perpetuamente ostensivas transmutam-se em um regime composto de signos que parecem indicar uma compreensão orgânica e estável da política com o comportamento e a vida, uma redução das expectativas na inspiração da história (história política, história das nações, história das instituições) e uma transferência dessas iniciativas ao campo do relato do cotidiano e da memorialística (memorabília), conferindo o condão da subjetividade às estratégias de contar, uma rubrica notadamente comunicativa, isto é, intersubjetiva. À sua maneira, a antropologia e a narrativa literária acusam essa tendência há certo tempo (Foster, 2001; Pratt, 1997), talvez em esforço para autonomizar-se de discursos que o tempo e a corrupção das práticas sociais tornou despóticos. 
Se houve uma poética histórica e nacionalista que se expandiu pelo planeta endossando o modelo de sistema-mundo (Andrew, 2006), agora no audiovisual medra uma estética transnacional (Nagib, 2006; Durovicova, 2010), mundializada, também ela imperativa em que pese seus esforços de discrição. Uma das peculiaridades dessa renovação está em que a noção de utopia, antes bastante vinculada às representações das lutas políticas de cunho progressista em cinematografias de regiões em circunstância de opressão, resvala-se a um modo de figuração apátrida embasada em uma virtualização do espaço que, ao invés de anônimo, é customizado, nem personalizado e nem sequer assujeitado. Em todo caso, nos habituamos a dizer não muito seriamente que se passou da tematização das causas para a dos efeitos (metalepse), o que se manifesta na predominância de uma espécie de multiculturalismo antropológico e politicamente correto a permear a voga do modo quase documental de figuração, apegado a um realismo/naturalismo em tudo avesso aos estímulos de um cinema espetacular de tipo blockbuster, ou mesmo de um cinema de ideias políticas grandiloquentes. Gerou-se uma tipologia de representação/apresentação sustentada por elipses e que, como produto final, se não em todos os casos parece industrializada, sinônimo de iconografia pasteurizada, agora que os editais se tornaram preponderantes quase sempre deixa entrever sua origem burocrática, subordinada à lei e a verbalizações que omitem sua origem disciplinar, controladora e autoritária.

A observância do regime político/ético/estético contemporâneo recomenda pouco barulho retórico e facilita a primazia de uma poética responsável, prudente e, se amiúde cautelosamente empobrecida, nem sempre deixa de instigar. E isso mesmo parecendo acompanhar o déficit de interesse pelos filmes e a míngua do público das salas de cinema e sua divisão em apenas dois seguimentos, intelectuais (adultos com vocação universitária e afeitos ao world cinema) e adolescentes (que incluem adultos infantilizados e crianças precocemente maduras, erotizadas, violentamente complexas). Um estudo da fração intelectualizada da audiência, com predileção por filmes de festivais, poderia ser revelador, por tabela, desse sujeito coletivo que encarnam os agentes produtores, técnicos e diretores do cinema 
contemporâneo do qual falamos. Revelaria ainda que a recepção participa ativamente da textualidade e da discursividade do cinema, dentro e fora da diegese, ideal ou empiricamente.

Uma vez que os ditames do world cinema são ratificados pelos milhares de festivais que hoje acontecem no planeta, mas culminância de uma série de forças sociais em prol dessa codificação (academia, meios de comunicação, instituições econômicas, políticas, enfim, a denominada esfera pública), percebe-se uma propensão ao retrato da naturalidade da vida cotidiana por parte dos produtores e diretores de filmes na atualidade, cientes de que devem seguir essa cartilha para almejar algum espaço. Pratica-se uma espécie de costumbrismo fílmico cosmopolita, com odes pausadas e descritivas à vida na pátria contemporânea. $\mathrm{O}$ espírito do tempo, a estrutura do sentimento e os agenciamentos levam a que haja uma língua fílmica seguida sem remorsos por boa parte dos praticantes do que alguma vez nomeamos poéticas da responsabilidade (Albano \& Lima, 2013).

No tocante às tendências de linguagem, da composição da imagem e do discurso, hoje se embaralham algumas referências formais e de conteúdo, as quais comentaremos, e sobretudo se exercitam em grande escala o que Jacques Rancière identificou como "fábula contrariada” e Gilles Deleuze como "situação ótica e sonora pura" (Rancière, 2005, p.19; Deleuze, 1985a, p.10). Trata-se de mitigar a tropologia representativa inerente às narrativas (a mimese e a verossimilhança do realismo narrativo sequencial e apegado à imitação reflexiva) e testar movimentos internos de sentido mediante a apresentação de composições afetivas (aquilo que se crê de difícil representação mas está aí como um modo de pensamento, talvez à espera de uma via de expressão menos desarticulada), guardadas as proporções, também um pouco como ocorre na literatura há certo tempo e nas demais artes visuais.

Como dissemos, os filmes figuram como nunca uma política da vida privada (?), em que os valores da cidadania estão intrínsecos, mostram uma existência geopolítica, promovem um ethos cosmopolita que poderia ser um dos adjetivos que definem uma parte da produção de cinema dos últimos 
lustros. Uma tal transnacionalização não atenua o travo de sujeição, apenas o registra como intersubjetividade ou como interdependência. Um dos fatores para que se atinja essa nota corresponde à crença indiscriminada na dimensão emancipadora da memória. Categoria que a depender do dispositivo que a atualize pode desvelar sua face catártica e libertária, no plano dos discursos epistêmicos tornou-se facilmente instrumento da história (história política, história da conservação das formas da imaginação cinematográfica, entre outras) devido ao processo de burocratização requerido pelos editais de apoio e pelos festivais que premiam filmes realizados mediante seus próprios fundos de financiamento.

Entre outras pretensões, nosso texto almeja ressaltar então a gestualidade, em modo de elipse a figurar o suposto filtro subjetivo da memória, em que a história e a política se manifestam como projeções da imaginação e da sensibilidade contemporâneas no cinema. As peças às quais nos referiremos são filmes narrativos (cujo prisma mimético atualizado favorece um tipo de verossimilhança), de aproximadamente duas horas e realizados em tradições culturais fortes, como a latino-americana. Esse pequeno complexo de características estabelece para nós o que entendemos por cinema aqui. Ademais, consideramos história e política àquelas séries cronotópicas explícitas que se realizam na diegese, no estilo ou na expressividade do filme, e levam a que nos remetamos ora a uma referencialidade exterior ao filme, ora à genealogia das imagens fílmicas às quais uma determinada obra se reporta ou mesmo à história das imagens e representações. Com efeito, ativa o fenômeno linguístico da pressuposição, isto é, a existência de um mundo antes e depois do filme do qual esse participa, em concordância temática ou mesmo formal (em qualquer caso sempre como um significante, nunca apenas como um significado), sem que se percam os traços do que lhe particulariza como alteridade, nem que seja efemeramente, isto é, sem que exclua o embate entre as diversas forças que atuam sobre as plataformas retóricas. Desse prisma, essas obras começam já in media res e o tropo da elipse, precisamente devido a isso, arremata o traço preponderante da dieta expressiva do cinema hoje. 


\section{Exposição}

Como referido, para seguir discorrendo acerca desses tópicos vamos nos concentrar em dois títulos recentes: Las marimbas del infierno (Julio Hernández Cordón, 2010) e O som ao redor (Kleber Mendonça Filho, 2012). Vejamos as sinópses:

1. Las marimbas del infierno (Guatemala-França-México, 2010). Don Alfonso toca marimba, o instrumento nacional da Guatemala. Mas seu velho instrumento está desatualizado e não desperta qualquer interesse. Blacko é um dos pioneiros do heavy metal na Guatemala e quando Alfonso e Blacko se conhecem e decidem combinar seus talentos em um novo projeto que una marimbas e heavy metal, uma série de percalços impede a concreção da empresa, muito embora o som produzido seja satisfatório. Esses obstáculos à criatividade são provocados pela perseguição de Don Alfonso pela Mara Salvatrucha, um grupo insurgente com viés violento e sem intenção política partidária, e pela falta de organização do estado para apoiar os projetos culturais locais.

2. O som ao redor (Brasil, 2012). A vida numa rua de classe-média do Recife toma um rumo inesperado após a chegada de uma espécie de milícia em pele de empresa de segurança particular. Quase todos os imóveis da área pertencem ao ex-coronel Francisco Oliveira, quem ali vive juntamente com vários de seus parentes muito embora mantenha uma fazenda de cana de açúcar e uma usina processadora de no município de Bonito, nos arredores da capital pernambucana. A região foi uma das principais produtoras de cana-de-açúcar no período colonial, como consequência grande receptora de escravos provindos do continente africano. Se a presença dos agentes de segurança privada aparenta trazer tranquilidade a uma rua da zona sul da capital, uma série de eventos ocorridos no passado condiciona sua presença à vida do patriarca Francisco Oliveira e sua história de coronelismo em Bonito.

Em ambos a via de causa/efeito dos processos sociais se reativa, incorporada ao modo em que a política em sentido convencional, a história da relação entre atos do estado, do governo e da sociedade, modula a diegese. Referimonos sobretudo a que existe certa tradição no cinema, bem exercitada na 
América Latina, em buscar uma descrição das causas de uma situação determinada de conflito entre o público e o privado. Por exemplo, em $O$ desafio (Paulo César Saraceni, 1965), vê-se como um estado autoritário e militarizado promove a violência social e por seu intermédio administra as relações com grupos antípodas e como esse plano macro está projetado em uma relação de casal. Em Las marimbas... e $O$ som... o mote são as consequências dessa rusga histórica (conservadores e militares contra o povo, fato miniaturizado em estudos de caso nos filmes) na conformação de um sentimento de revanche que se incorpora no presente em grupos criminosos talvez herdeiros dos capitães do mato, dos insurgentes, dos militares, dos paramilitares que durante alguns séculos disputaram o espaço e a palavra na região da América Central e do subcontinente brasileiro. De fato, revanchismo, raivas e humores correlatos compõem o horizonte afetivo principalmente de $O$ som ao redor, já que o filme de Cordón polvilha mais a fruição com melancolia e graça.

Mesmo assim, em Las marimbas del infierno a questão inicialmente externa da Mara Salvatrucha permeia o desenvolvimento da vida do personagem Alfonso, que teve de retirar a família de casa por conta das ameaças aparentemente gratuitas de integrantes do grupo e caminha empurrando sua marimba por uma cidade caótica e colorida, tomada em muitos planos médios e alguns gerais, bem controlados pelo sistema expressivo que segue o filme. Esse dado cronotópico externo completa a elipse, um tropo interno, acerca das agruras pelas quais passa don Alfonso. Está predeterminado o cenário social/nacional em que as funções diegéticas dos personagens são desempenhadas, personagens que são construídos como objetos dos efeitos deletérios de ações políticas equivocadas. A propósito, o filme faz dessa possibilidade esporádica uma espécie de técnica narrativa de esclarecimento. Veja-se o encontro de Alfonso com uma lenda do heavy metal guatemalteco, Roberto "Blacko", do pesado Guerreros del metal, antes Sangre humana. Em que pese a anuência em ensaiar e o bom som retirado da fusão da marimba com os instrumentos básicos do rock, proposta de Alfonso, alguns percalços em modo de motivos literários e sociais se apresentam para frustrar a criatividade: 
1- o arquétipo do pícaro, constante da tradição literária espanhola (la picaresca), encarna em Chuiquilín, um ex-presidiário que para sanar dívidas de uma namorada empenha a marimba que lhe foi confiada por Alfonso.

2- a mulher como elemento de desestabilização de uma conjuntura.

3- as irremediáveis aflições econômicas a invocarem as alegorias do subdesenvolvimento capitalista centro-americano ao sustar a iniciativa de os nativos participarem ativamente da elaboração e reelaboração das formas culturais hegemônicas (marimbas + guitarra, bateria, baixo ou Alfonso + Blacko).

Repare-se que os modelos de representação, ou melhor, de figuração (figuração remete mais ao dado produtivo e menos ao reprodutivo, ambos, produção e reprodução, tensionados na imagem fílmica), passam de uma tentativa de explicação geral e já bastante frequente nas ciências sociais, isto é, em discursos fora do âmbito do filme forçados para dentro, para uma introspecção retórica das consequências dessa tendência histórica. Então, percebe-se que uma das maneiras em que o cinema soluciona essa dialética entre formas e conteúdos internos e externos, e que seja em si mesmo uma prática política, transparece no fato de que há um regime de percepção e de pensamento que orienta sua concepção estética, mas essa determinação pode ser processada com o intuito de gerar formas inéditas de experiências sociais e afetividades, como mais ou menos ocorre nos filmes de 2009 e 2012.

Em ambos é notável a tentativa de reconfiguração da sensibilidade por intermédio do audiovisual, do cinema, pois deles surgem novas configurações de temporalidade, de espacialidade, de relações humanas, ao menos em relação à tradição cinematográfica da região. Agora bem, os sintomas dessa mudança de horizonte entre as películas ensaísticas latinoamericanas do Nuevo Cine dos anos 1950, 1960 e 1970 e os filmes realizados na conjuntura posterior às ondas liberais da economia política internacional dos últimos 30 anos são ostensivos no entramado emocional dos diálogos, elaborados e sentenciosos na referida película de 1965 ( $O$ desafio), por exemplo, e episódicos e improvisados nos que ora nos ocupamos. Tais sintomas não estão contidos apenas no aspecto dramatúrgico propriamente 
da formação dos personagens, mas na direção de arte, nos modos do enquadramento, nas opções da câmera na focalização das locações etc. Contam ainda o barateamento e a cada vez maior mobilidade da aparelhagem técnica audiovisual, um dado escamoteado, mas que incorre no destino das imagens como um todo.

Entre Las marimbas... e O som..., por certo, apenas salientaremos a quase imobilidade dos planos e sua duração alargada para não exagerar a trilha das analogias formais com outros filmes que igualmente remetem a um gosto e uma sensibilidade narrativa já bem assentados no regime de percepção e pensamento mencionados, relativo ao que hoje mais ordinariamente se denomina world cinema (caudatário de um certo olhar etnográfico manifesto, com pulsão de documento, mediado pelo quase cacoete da elipse a contrariar o desenrolar esclarecedor da fábula). Recordaremos dois recursos de exceção a essa imobilidade em cada obra a fim de salientar os logros. Primeiro, o plano sequência do início de $O$ som..., quando uma estranha e veloz perseguição às crianças de bicicleta e patins no playground do edifício de classe média (talvez inspirado em O iluminado, Stanley Kubrick, 1980) culmina em uma quadra poliesportiva ao ar livre onde babás de pele mais escura paparicam crianças de pele mais clara. Por certo, toda a sequência, que envolve um uso inspirado dos recursos sonoros, configura-se como um ponto alto de certa tradição cinematográfica regional ao coadunar estímulos de ordem sociológica e estética, esquema expressivo que nos causa a impressão de estar sempre em estado de latência nos discursos gerados por aqui. Outra exceção importante encontra-se no uso do malfadado zoom,

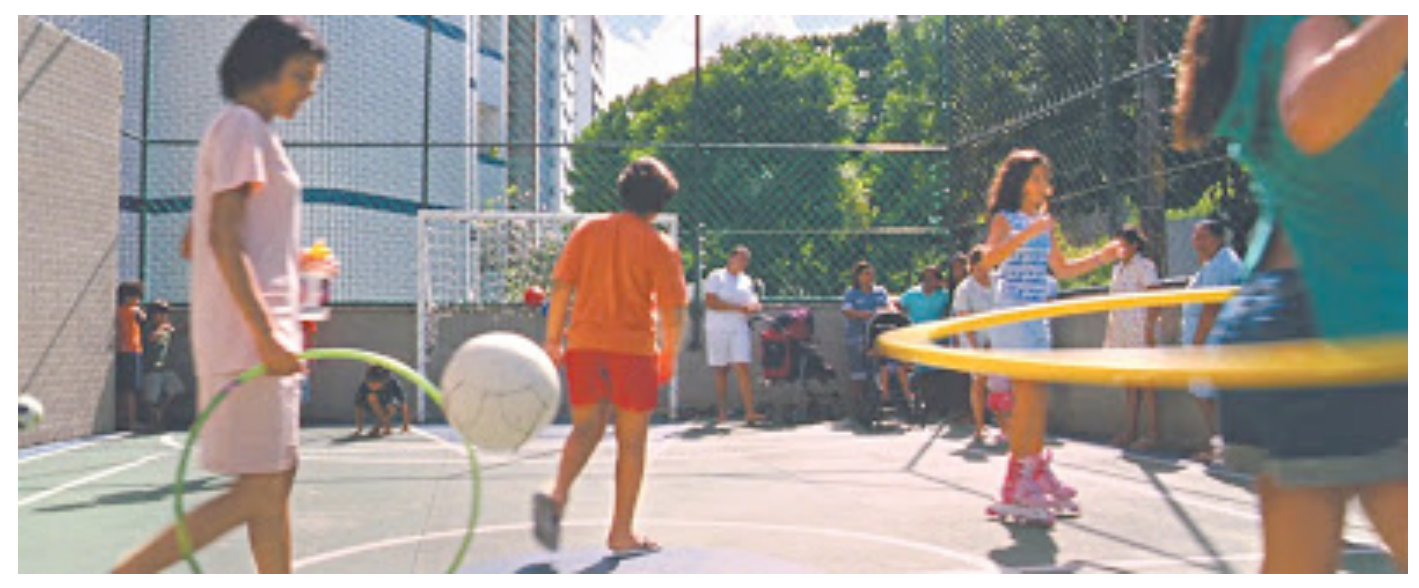


ativado em diversas ocasiões também com boa fatura, com destaque para a sequência de João e Sofia entre as ruínas do cinema nas terras de seu Francisco em Bonito.

Já em Las marimbas... a direção de fotografia aproveita mais as andanças de Alfonso e Chiquilín e, internamente, isto é, com movimentos dentro do quadro, sem locomoção da câmera, tira bom proveito dos ensaios e do frenesi das cabeleiras infernais. Além disso, chama a atenção uma sequência cuja ressonância ética e estética é formidável. Trata-se da reconstrução de um motivo bem particular (tropo, imagem, tipo) surgido há pelo menos oitenta anos no cinema, desde Zero de conduta, Jean Vigo, 1933. Sua frequente ocorrência no audiovisual contemporâneo pode estar condicionada a certo elã de transgressão e libertação política que ainda mantém a rebelião com travesseiros no dormitório do internato no filme francês, traduzidos por Cordón no uso de drogas e nos pulos de Chiquilín com a namorada na cama de hotel em Marimbas.

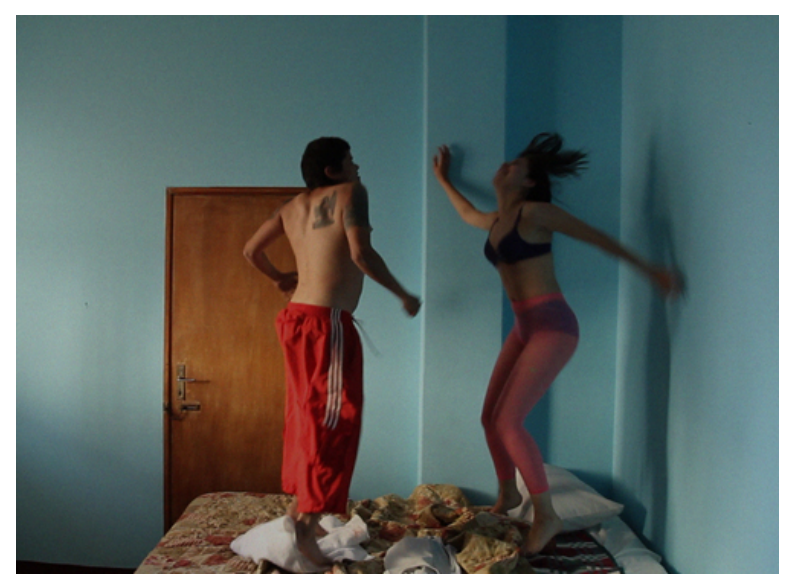

Falando nisso, certa vez Joaquim Pedro de Andrade (1976) escreveu um manifesto em que disse não crer na força política do cinema, porque tão somente a política direta era eficaz, mais ainda em face das acusações de tortura que grassavam pela América Latina então. Portanto, se existe um conteúdo político no cinema esse só pode ser indireto, segundo ele. Mas o cinema como uma forma de pensamento e de consciência roça a apresentação de modalidades políticas convencionais ou novas e às vezes até pretende ser um comentário a uma situação política de vulto, como não raro ocorre com resultados bisonhos, quando os significantes da história e do 
cinema se encontram e se estranham. Por não mencionar que o cinema é um discurso social cujo suporte demanda quantias não baixas de investimento pecuniário e entre as cláusulas dos editais das políticas para a cultura dos estados nacionais ou das fundações e corporações que apoiam a realização (e às vezes a distribuição e a exibição) de um certo tipo de filme habitam diretrizes que agenciam os regimes de representação e apresentação. Sem falar ainda em seu caráter mundializado, ou seja, em que a adoção de políticas de incentivos ao audiovisual em boa parte do planeta segue uma linha mais ou menos comum. E sem falar também nos modelos de mundo plasmados nos filmes a inscreverem não apenas ideias e deíticos culturais isolados, mas sensibilidades, afecções e afetos previamente politizados e em seguida repolitizados nos meandros da fábula, devido àquela capacidade de remodular o espaço, o tempo e as relações dos corpos e dos sujeitos dentro desse marco.

No nosso caso, em que ambos os filmes começam com uma apresentação documental, expõe-se desde o início um programa estético e ético composto por signos da memória subjetiva em Marimbas... e da memória nacional em O som.., a despeito de estarem reinterpretados pela história transnacional e acabarem ensejando um temperamento dramático, narrativo e plástico ao mesmo tempo inaudito e familiar aos latino-americanos, vezados nos procedimentos da dialética, os fáceis e os que superam esse expediente.

Enquanto Las Marimbas... abre com um testemunho de don Alfonso a um interlocutor oculto em que afirma ser ameaçado pelo grupo criminoso $L a$ Mara Salvatrucha, O som... inicia com fotografias de plantações de cana, de usinas, de casas grandes, de tipos humanos da zona da mata açucareira do nordeste do Brasil, ainda que nenhum dos dois se proponha ao ensaio. $O$ som... às vezes se mostra proclive para essa direção, notadamente na sequência do almoço de Francisco com João e Sofia na fazenda ou com a revelação de Clodoaldo e Cláudio ao final. Mas como o filme apresenta incursões por vários esquemas genéricos (lugares comuns da comédia, do terror, do thriller, dos filmes $b$, da nouvelle vague etc.) esse sinal ensaístico se torna, elipticamente, mais uma figura de gênero. Com efeito, repete-se o uso da elipse diegética preenchida pela história, patente no entramado que se 
estende entre as fotomontagens do início e o reencontro dos filhos de Antonio, o capataz morto em 1984, com Francisco ao final. E também, com consequências diversas, por se não ter ciência de se o representante contemporâneo do senhor do engenho, Francisco, por fim revelado como uma espécie de vilão, deveras foi abatido por seus capatazes, deixando em suspensão uma peripécia de compensação de classe. Observa-se aí a propensão a representar experiências relativas ao ressentimento advertida por Ismail Xavier (2001) no cinema brasileiro dos anos 1990, mas que ainda se pode vislumbrar na atualidade. Essa indeterminação dos sintagmas que enfeixariam certos significados da memória são preenchidos em parte pela onipresença dos sentidos da história.

Mas o fato é que nem no filme guatemalteco nem no brasileiro há inclinação por um aprofundamento na realidade dos motivos dos eventos históricos que, não obstante, parecem redundar em boa parte dos sentidos internos, talvez naquela busca por outra realidade ou no exercício da simples constatação da realidade diegética (afinal, o que podemos chamar hoje de realidade se não uma série de enunciados autorreferenciais?). Inclusive, sem nunca almejar o retrato social ou mesmo uma exposição de verdades, em Marimbas... ao final há uma inscrição comentando o caráter heróico dos artistas no país (já explicitamente a Guatemala, na América Central), tal como Alfonso, Blacko e o pícaro Chiquilín, os personagens centrais que tentaram emplacar Los guerreros del metal, a banda de heavy metal com baixo, bateria e guitarras, turbinada pelo instrumento que se quer vernáculo.

Mesmo esse anúncio, assinatura do personagem diretor do filme (?), não convence como um desabafo de um sujeito autoral em busca de seu leitor ou espectador, mas pode se configurar como outro dado estilístico recorrente na América Latina do pós-ditaduras militares, o recurso da autoficção, ainda que agora elipticamente. Em Marimbas... não há propriamente o desenvolvimento de uma autoficção, apenas se atualiza o contrato de verossimilhança entre ficção, imaginação e o que se considera o mundo da vida, entre o visível e o invisível. No caso, o uso da voz do personagem autor na fábula acena para nossa tradição de didatismo, mas mediante a conjuntura estilística que Beatriz Sarlo alcunhou de giro subjetivo (2005). O 
cinema já havia experimentado algumas incursões nesse sentido, cujos componentes expressivos já se encontram no cinéma vérité e no direct cinema, mas essa virada que se afirma agora também tem raízes nas discussões metodológicas da antropologia de meados do XX. No cinema hoje se manifesta de diversos modos, com uma predileção pela variantes voice over e off, em que um narrador dentro ou fora do campo de visão conta com sua própria voz e sob sua consciência uma história ou parte dela (lembramos agora de Millenium Mambo, Hou Hsiao-Hsien, 2001, alguns filmes de Wong Kar Wai e recentemente de Tabu, Miguel Gomes, 2012).

Decerto, o reputado giro antropológico ou subjetivo, a noção de transnacionalidade e a referida figura da elipse sintetizam uma parte das sugestões do panorama epistemológico e poético contemporâneo e se manifesta como produção e produto mais afinado da imaginação social que vem se instaurando há certo tempo. Para ilustrar, se tributários inconscientes da sugestão antropológica de se realizar uma fenomenologia da cultura (Geertz, 1997), muitos filmes, especialmente os que nos concernem aqui, redundam na solução visual e diegética de evidenciar, figurativamente e sem elementos críticos articulados, a divisão internacional do trabalho quando incorrem em uma espécie de descrição densa (Geertz, 1978) do momento histórico em que se vive nas regiões sugeridas (patente no ritmo pausado dos cortes, nos quadros que conotam observação atenta, talvez profissional). Há mais descrição (densa ou rala) que interpretação crítica, em escala de superávit de um e déficit do outro.

No caso de Marimbas... a incapacidade de uma modernização capitalista (vejam-se o tipo de locações, a ausência de clientela nos bares e nas lojas frequentadas pelos personagens), a falência das instituições do estado (no momento em que Chiquilín busca por apoio público no departamento de Cultura do governo local) são uma fala menos crítica que naturalizada da circunstância repudiada com humor fatalista e sottovoce. Em O som... assombra a invariável injustiça da distribuição de renda e das brechas raciais, a segurança pública em mãos privadas (subvertendo uma das premissas fundadoras do estado moderno, em que a segurança é monopólio estatal) etc. Essa posição formalmente discreta diante das mazelas humanas não 
encontra em $O$ som...nenhum sinal de vitimização e, ademais, pode ser lida como uma vontade enérgica de parte dos agentes envolvidos na feitura do filme, concentrados em seu diretor, Kleber Mendonça Filho, em participar de um certo código predominante de interpretação do mundo, cujas forças motrizes se encontram no movimento histórico liberal (na pior acepção do termo) que vem arranjando as conjunturas em que as obras se materializam principalmente a partir do Consenso de Washington. Segundo essas proposições, então, em linhas gerais tanto Marimbas... como $O$ som... podem até remeter àquela reinterpretação que o outro parece fazer de si mesmo por intermédio da linguagem normativa, a linguagem do colonizador (Pratt, 1997, p. 28), sempre e quando essa suposição não seja aceita por seu valor de face, sem problematizações.

\section{4. Últimas considerações}

Ao longo do estudo observamos então que esses dados referidos estão em benefício dos bons resultados dos filmes, mas isso se deve sobretudo a que atestam um regime poético e epistemológico convocado e disposto com destreza. Sugere sobretudo a habilidade alcançada para o uso da elipse como dispositivo de redução de explicações sociológicas, de refino de teses densas agora inferidas na diege, no discurso e na fábula dos filmes, o que em várias ocasiões classificamos de estilo ensaístico.

Por exemplo, a virada subjetiva detectada nos estudos literários e fílmicos pelos estudos culturais incita a formação de regimes de verdade, ou melhor, da fixação de um só regime de verdade (a figuração do mundo da vida pelo realismo/naturalismo, os conteúdos diegéticos inclinados para a subalternidade, o mundo ampliado e em aparência não-europeu, a iconografia descentrada, o politicamente correto apimentado, a história das imagens em lógica de revisão, os tais simulacros etc.), uma discussão corrente há pelo menos 40 anos nos centros acadêmicos com autoridade epistemológica e hoje consolidada em todos os discursos reconhecidos socialmente. Essa virada subjetiva, hoje ela mesma dominante, obrou em desfavor das narrativas históricas grandiosas e definitivas e franqueou as 
projeções da memória, o que também favoreceu o deslocamento dos ensaios fílmico-sociológicos típicos do realismo da segunda metade do século XX, para uma tática considerada contra-hegemônica de observar de acordo com a subjetividade dos que outrora eram considerados invisíveis, nunca sujeitos de enunciação.

Não obstante, estabelecido que o cronopos sócio-histórico é uma constante entre os recursos estilístico dos romances e filmes latino-americanos, comparado com as exposições de motivos para o desacordo com a situação social proferido pelos personagens dos filmes do chamado Nuevo Cine Latinoamericano dos anos de 1960, os filmes contemporâneos são notáveis exemplares de uma renovação de fundo nos expedientes que caracterizam os modos de emprego desse recurso antes e agora, malgrado a tendência ao cronotopo histórico-social se mantenha. Percebe-se ao longo do estudo, todavia, que essa reforma veio incentivada mais que por uma nova sensibilidade talvez provocada por uma autoanálise, mas por transformações globais nos regimes de produção e, certamente, nos regimes de representação do cinema contemporâneo, muito afeitos ao realismo/naturalismo, à cronotopia, mas também muito habilidosos para a figuração dos motivos sociais. Basta recordar a parte influente do cinema iraniano, chinês (principalmente de Taiwan e de Hong Kong), tailandês, filipino, coreano etc., aquela que tem despontado nos festivais europeus nos últimos quarenta anos.

Então, essa constância entre a tradição latino-americana, a recorrente remissão ao vezo ensaístico (cronotopia sócio-histórica), com os estímulos estéticos do cinema contemporâneo, encontra um registro retórico plausível e até mesmo cômodo, uma vez que indica que a producão regional está atualizada ou, em uma conclusão mais eufórica, que houve uma latinoamericanização do cinema, uma vez que muitas das marcas dos Nuevos Cines do decênio de 1960 reaparecem hoje (notadamente a primazia dos conteúdos engajados ou miserabilistas), o que os filmes aqui examinados dão conta. No entanto, essas novas modalidades reproduzem uma orientação do olhar que encerra algumas doses de energias líricas liberadoras e muita remissão aos estatutos estéticos vigentes, em que a elipse é a figura mediadora dos 
enunciados da história, da memória, da política e a noção de transnacionalidade se impõe como um logos, uma razão conciliadora e incontornável corolário da globalização.

\section{Referencias bibliográficas}

Albano, S. G.; Lima, M. E. O. (2013). Utopia capitulada e outros temas do cinema latino-americano. Mídia e Cotidiano, 1 (1), pp. 60-82.

Andrade, J. P. (1976). La política indirecta. En P. René; M. Daniel (Ed.), El cine latinoamericano. Madri: Sedmay, pp.76-79.

Andrew, D. (2006). Islands in the sea of cinema. En Hill, J.; R. Kevin. National Cinemas and World Cinema, Studies in Irish Film 3. Portland: Four Courts Press, pp. 256-271.

Deleuze, G. (1985a). La imagen-movimiento (trad. de Irene Agoff). Barcelona: Paidós.

Deleuze, G. (1985b). La imagen-tiempo (trad. de Irene Agoff). Barcelona: Paidós.

Deleuze, G. y Félix, G. (1995). Mil platôs. Capitalismo e esquizofrenia (trad. de Aurélio Guerra Neto, Ana Lúcia de Oliveira \& Célia Pinto Costa et al). São Paulo: Editora 34.

Durovicova, N. (2010). Preface. En Durovicova, N. World Cinemas, Transnational Perspectives. Nova York/Londres: Routledge, pp. IXXV.

Foster, H. (2001). The Return of the Real. The Avant-Garde at the End of the Century. Cambridge/Londres: MIT Press.

Geertz, C. (1978). A interpretação das culturas (trad. de Fanny Wrobel). Rio de Janeiro: Jorge Zahar.

Geertz, C. (1997). O saber local: novos ensaios em antropologia interpretativa. (trad. de Vera Mello Joscelyne). Petrópolis: Vozes.

Nagib, L. (2006). A utopia no cinema brasileiro. Matrizes, nostalgias, distopias, São Paulo: Cosac \& Naify.

Pratt, M. L. (1997). Ojos imperiales. Literatura de viajes y transculturación. Buenos Aires: Universidad Nacional de Quilmes.

Rancière, Jacques (2000). Le Partage du sensible: esthétique et politique. Paris: La Fabrique.

Rancière, Jacques (2005). La fábula cinematográfica (trad. de Carles Roche). Barcelona: Paidós.

Sarlo, B. (2005). Tiempo pasado. Cultura de la memoria y giro subjetivo. Una discusión? Buenos Aires: Siglo XXI. 
Xavier, I. (2001). Figuras do ressentimento no cinema brasileiro dos anos 90. En Ramos, F. P. et altri (orgs.). Estudos de Cinema 2000 - SOCINE. (pp. 78-98). Porto Alegre: Sulina.

Cómo citar: Guilherme Albano, S. (2014). "Elipse, história, política, memória. Las marimbas del infierno e $O$ som ao redor". Fotocinema. Revista científica de cine $y$ fotografía, 9, pp. 65-83. Disponible: http://www.revistafotocinema.com/index.php?journal=fotocinema 